soon after the operation from traumatic shock or exhaustion; others from acute peritonitis, both septic and aseptic. Finally, some have survived the operation for periods varying from ten to thirty days, and have then succumbed to various intestinal disorders. Amongst eight operations there has been only one arerred success. The results so far are discouraging, but it is to be hoped that in the future, the diagnosis becoming more precise, we shall be able to operate at a more favourable time, when the tumours have not acquired so great a size, and that then the chances of cure will be more favourable.

Those who require to investigate this subject more fully may refer to the article on Lipoma by Cornil in the "Dictionnaire Encyclopédique des Sciences Médicales," to the "Traité de Pathologie Externe," by Follier and Duplay, and the "Traité des Tumeurs Abdominales," by Péan. Both of Sir Spencer Wells's cases are related in his work on the "Diagnosis and Surgical Treatment of Abdominal Tumours," pp. 204 and $205 .-\mathrm{I}$ am, Sir, yours obediently, Jan. 1886. G. R. HAMERTON, M.D.

\section{"A CASE OF TUBAL PREGNANCY."}

To the Editor of THE LANCET.

Sin,-In reference to the case of supposed tubal pregnancy recorded by Dr. Hay in The LaNCET of Jan. 16th, whatever may be the true explanation of the condition, the theory propounded will gain nothing from reference to the case referred to as having recently been brought forward at the London Obstetrical Society, which on further examination by a committee of Dr. Herman and Mr. Doran was found to be wanting in any kind of corroborative evidence in favour of its supposed nature. There was no abnormality of the woman's pelvic organs to be discovered, and the specimen presented the usual characters of intra-uterine pregnancy (the decidua of which is quite different from the corresponding structures developed in all cases of extrauterine gestation); there was, in fact, not one particle of evidence in favour of the strange story related.

The history of Dr. Hay's case, as given in THe LANCET, appears to be conclusive in establishing the fact that the foetus expelled was intra-uterine at the time of examination, for the introduction of the probe was followed by hæmorrhage, and abortion took place three days after. The probability of the passage of a four-months' tubal pregnancy on two occasions into the uterus under the circumstances described is altogether incredible, the supposed gestation cyst being disconnected with the uterus; a dilatation of its tubal pedicle sufficient for the purpose is impossible. The diagnosis of tubal pregnancy is seldom correctly made; the condition is rarely suspected when it dees occur, and when it is suspected it usually turns out to be a mistake, and the woman is fortunate who escapes abdominal section for what proves to be a normal intrauterine pregnancy. I am, Sir, yours obediently,

Harley-street, Jan. 30th, 1886. W WLTER S. A. GRIFFITH.

\section{THE SCARLET FEVER OUTBREAK IN MARYLEBONE.}

To the Editor of The LANCET.

SrR,--I have read your article in THE LANCET of Jan. 23rd regarding an outbreak of scarlet fever in Marylebone, supposed to be caused by milk derived from a farm in this district, and must deprecate the publication by Mr. Wynter Blyth of a number of statements respecting a Hendon farm, the majority of which I have reason to know are based on conversations that Mr. Blyth had with Mr. Power and myself. I need hardly say that these conversations, the primary object of which was to protect London consumers from danger, did not contain all or nearly all the facts that are accumulating respecting the relations of milk and scarlet fever, and submit that the public should wait for Mr. Power's report, which will embody the results of our united investigations here, before arriving at any definite conclusion upon the matter under inquiry. Under the circumstances, I cannot but think that Mr. Blyth would have done well to confine his report to matters which came under his own observation in his own district.

I am, Sir, yours truly,

January 2äth, 1886.

\section{BIRMINGHAM. \\ (From our own Correspondent.)}

\section{PRESCRIBING CHEMISTS.}

THE Deputy Coroner, at a recent inquest on the body of a child nine months old, expressed his opinion that the question of prescribing by chemists might properly be taken up by the medical associations. There is no doubt that the custom is an evil one, and that a large business is done by prescribing over the counter. Considerable harm, especially to children, is the result of this practice. A sense of responsibility hardly enters with the recommendation to give certain medicines, which are promptly made up, and charged for accordingly. The poor and ignorant appear to accept the belief that a knowledge of compounding drugs is equal to the knowledge required in prescribing them. Certainly there is a vast amount of credulity among the British public in this respect, which affords an extensive market for this vicious practice. Until the law affecting unqualified practitioners is better defined and easier of application, these cases will still frequently occur, and reflect discredit upon the intelligence of those who are made the dupes, and very often the victims, of this mode of treating disease.

INGLEBY LECTURES.

On the 28th ult., the second of the two Ingleby lectures was given by Dr. Wade, before a large and appreciative audience, the subject being "Nervous Diseases of Women." The main characteristics of the two sexes were pointed out, and the subject of hysteria was carefully dealt with. The many and various symptoms were aptly illustrated from the lecturer's experience, while the known shrewdness and attention he has given to the investigation of this class of disorders allowed him to speak with force and authority. The usual vote of thanks was passed.

HOSPITAI SUNDAY FUND.

A project has been mooted to divide pro rata the proceeds of this fund among all the charities of the town. Hitherto the two largest-the General and Queen's Hospitals-have divided equally in respective years, and the fourteen amalgamated charities have taken one share. The manifest injustice to the Queen's Hospital, which is sadly in want of additional funds, allowed the matter, fortunately, to fall through, and thus the institution will be relieved of a great source of anxiety. The meeting of the General Committee of the Hospital Saturday movement was marked by the reports sent in from the representatives appointed to the various charities. These reports were unanimous in their testimony as to the efficiency and economy with which the charities are administered, and afford a practical commentary for the working population of the town. In the face of declining subscription lists in many directions, it is of importance that it should be recognised how the many may help the few; and while the suffering poor in the district come from the working class mainly, this movement exhibits clearly the forcible application of the widest charity being not only possible, but of the greatest service to fellowworkmen.

\section{EDTNBURGH.}

\section{(From our own Correspondent.)}

NEW UNIVERSITY LECTURESHIP.

Aт a meeting of the Senatus Academicus of the University of Edinburgh held last week it was decided to found a new lectureship on the Philosophy of Natural History in connexion with the natural history department, and Mr. G. J. Romanes, F.R.S., was appointed lecturer. The appointment is for five years, and it is announced that $\mathrm{Mr}$. Romanes will give his first course of lectures, six in number, during next winter session. The lectureship has been endowed by a munificent bequest by Lord Rosebery, who was Lord Rector of the University from 1880 to 1883 , and who has always taken the warmest interest in university affairs. This is the second lectureship which has been recently created in connexion with the natural history department, at the suggestion of Professor Cossar Ewart, the first being a lectureship on Comparative Embryology, on which subject one course 